\title{
UMUR IBU DAN PARITAS SEBAGAI FAKTOR RISIKO YANG MEMPENGARUHI KEJADIAN ANEMIA PADA IBU HAMIL DI WILAYAH KERJA PUSKESMAS AMPENAN
}

\author{
Aulia Amini, Catur Esty Pamungkas, Ana Pujianti Harahap \\ Universitas Muhammadiyah Mataram, aulia.amini@ummat.ac.id
}

\section{INFO ARTIKEL}

Riwayat Artikel:

Diterima: 19-07-2018

Disetujui: 26-07-2018

\section{Kata Kunci:}

Usia lbu

Paritas

Anemia lbu Hamil

\section{ABSTRAK}

Abstrak: Anemia adalah suatu keadaan dimana kadar hemoglobin $(\mathrm{Hb})$ atau jumlah eritrosit lebih rendah dari kadar normal. Pada wanita hamil dikatakan mengalami anemia jika kadar $\mathrm{Hb}<11 \mathrm{~g} / \mathrm{dl}$. Data Riskesdas (2013) prevalensi anemia pada ibu hamil di Indonesia sebesar $37,1 \%$ [1]. Anemia dapat menyebabkan komplikasi yang lebih serius bagi ibu dalam kehamilan, persalinan dan nifas yaitu dapat megakibatkan abortus, partus prematurus, kelahiran bayi prematur, berat bayi lahir rendah, perdarahan postpartum karena atonia uteri, syok, dan infeksi intra partum maupun postpartum (Depkes RI, 2010). Data di Provinsi NTB tahun 2015 sebanyak 56,5\% ibu hamil terkena anemia. Puskesmas Ampenan merupakan puskesmas yang memiliki kasus anemia tertinggi di Kota Mataram yaitu sebesar 16,67\% (139 kasus). Tujuan penelitian diketahuinya faktor risiko yang mempengaruhi kejadian anemia pada ibu hamil di wilayah kerja Puskesmas Ampenan. Rancangan penelitian yang digunakan adalah cross sectional, dilaksanakan di Puskesmas Ampenan. Sampel penelitian semua ibu hamil yang anemia di wilayah kerja Puskesmas Ampenan sebanyak 64 orang. Teknik pengambilan sampel secara total sampling. Analisis data meliputi analisis univariat dan bivariat dengan uji Chi Square dengan tingkat kemaknaan $p<0,05$. Hasil penelitian analisis bivariat menunjukkan bahwa ada hubungan yang bermakna antara usia ibu dengan anemia ( $p$ value $0,017<0,05$ ), dan tidak terdapat hubungan yang bermakna secara statistik antara paritas dengan kejadian anemia pada ibu hamil ( $p$ value 0,092 $>0,05$ ). Disimpulkan usia ibu yang berisiko ( $<20$ tahun dan $>35$ tahun) dapat menyebabkan anemia dalam kehamilan.

\begin{abstract}
Anemia is a condition where the hemoglobin $(\mathrm{Hb})$ or erythrocyte count is lower than normal. In pregnant women said have anemia if the $\mathrm{Hb}$ content $<11 \mathrm{gr} / \mathrm{dl}$. Data Riskesdas (2013) prevalence of anemia in pregnant women in Indonesia amounted to $37.1 \%$. Anemia can cause more serious complications for pregnancy mother, childbirth and childbirth that can caused abortion, prematurus, premature birth, low birth weight, postpartum hemorrhage due to uterine atony, shock, intra partum and postpartum infections (Depkes, 2010). Data in the province of NTB in 2015 as much as 56.5\% of pregnant women affected by anemia. Puskesmas Ampenan is health center that has the highest anemia case in Mataram city that's equal to 16,67\% (139 cases). The purpose of the research is to know the risk factors that affect the incidence of anemia in pregnant women in Puskesmas Ampenan work area. The research used cross sectional design, implemented in Puskesmas Ampenan. Sample of this reasearch is all pregnant women anemia in work area of Puskesmas Ampenan (64 people). Sampling used total sampling. Data analysis included univariate and bivariate analysis with Chi Square test with significance level $p<0,05$. The result of bivariate analysis showed that there was a significant correlation between maternal age with anemia ( $p$ value 0,017 <0,05), and there was no statistically significant relationship between parity and incidence of anemia in pregnant women ( $p$ value 0.092>0.05) Concluded maternal age at risk ( $<20$ years and $>35$ years) can cause anemia in pregnancy.
\end{abstract}

\section{A. LATAR BELAKANG}

Anemia adalah suatu keadaan dimana kadar hemoglobin $(\mathrm{Hb})$ atau jumlah eritrosit lebih rendah dari kadar normal. Pada wanita hamil dikatakan mengalami anemia jika kadar $\mathrm{Hb}<11 \mathrm{~g} / \mathrm{dl}$. Komplikasi yang menyertai kehamilan diantaranya adalah penyakit kurang darah (anemia). Anemia umumnya disebabkan karena kekurangan zat besi [2]. Menurut WHO (2015) secara global, prevalensi anemia pada ibu hamil di seluruh dunia adalah sebesar 41,8 \% dari ibu-ibu yang sedang hamil [4]. Prevalensi anemia pada ibu hamil diperkirakan di Asia sebesar 48,2 \% , Afrika 57,1 \% , Amerika 24,1 \% , dan Eropa 25,1 \%. Anemia lebih cenderung berlangsung di negara yang sedang berkembang dari pada di negara yang sudah maju 36 \% yang disebabkan oleh kekuraangan asupan zat besi, peningkatan kebutuhan fisiologis dan perdarahan [4].

Berdasarkan hasil data Riskesdas (2013) prevalensi anemia pada ibu hamil di Indonesia sebesar 37,1 \% [1]. 
Untuk mengatasi atau mengurangi prevalensi anemia pada ibu hamil di Indonesia, pemerintah Indonesia mengatasinya dengan pemberian tablet tambah darah ( $\mathrm{Fe})$. Pada tahun 2011 pemberian tablet Fe mencapai 83,3\% dari jumlah ibu hamil, meningkat pada tahun 2012 sebesar $85 \%$. Meskipun pemerintah sudah melakukan program penanggulangan anemia pada ibu hamil yaitu dengan memberikan 90 tablet $\mathrm{Fe}$ selama periode kehamilan dengan tujuan menurunkan angka anemia pada ibu hamil, tetapi kejadian anemia masih cukup tinggi [6].

Anemia kehamilan atau kekurangan kadar hemoglobin (Hb) dalam darah dapat menyebabkan komplikasi yang lebih serius bagi ibu dalam kehamilan, persalinan dan nifas yaitu dapat megakibatkan abortus (keguguran), partus prematur, kelahiran bayi prematur, berat bayi lahir rendah, perdarahan post partum karena atonia uteri,syok, infeksi intra partum maupun post partum [2]. Data di Provinsi Nusa Tenggara Barat tahun 2015 terdapat sebanyak $56,5 \%$ ibu hamil yang terkena anemia. Data dari Dinas Kesehatan Kota Mataram tahun 2015 prevalensi anemia pada ibu hamil adalah sebesar 8,11\% (804 kasus), Puskesmas yang paling rendah kasus anemia adalah Puskesmas Dasan Cermen sebesar 1,63 \% (11 kasus),dan Puskesmas yang masih tinggi kasus anemia adalah Puskesmas Ampenan yaitu sebesar 16,67\% (139 kasus) [7].

Anemia pada kehamilan disebabkan oleh beberapa faktor, antara lain yaitu faktor usia ibu dan paritas [8]. Usia ibu yang terlalu muda $(<20$ tahun $)$ belum siap memperhatikan lingkungan yang diperlukan untuk pertumbuhan janin. Ibu yang memiliki anak lebih dari tiga juga merupakan salah satu faktor yang menyebabkan terjadinya anemia selama masa kehamilan. Hal ini disebabkan karena terlalu sering hamil dapat menguras cadangan zat gizi tubuh ibu [9]. Kebanyakan anemia yang diderita masyarakat adalah karena kekurangan zat besi. Untuk mengatasinya pemberian zat besi (tablet Fe) secara teratur dan peningkatan gizi teratur pula [10]. Pemanfaatan kesehatan untuk dunia dalam strategi bidan dalam peluang kerja yaitu dimana tenaga bidan masih dibutuhkan dalam pelayanan kebidanan guna untuk menurunkan angka kejadian anemia pada ibu hamil.

\section{B. METODE PENELITIAN}

Rancangan yang digunakan dalam penelitian ini adalah cross sectional. Populasi dalam penelitian ini adalah semua ibu hamil yang mengalami anemia di wilayah kerja Puskesmas Ampenan pada bulan Januari - Juli tahun 2017 sebanyak 68 orang. Sampel yang digunakan adalah semua ibu hamil yang anemia di wilayah kerja Puskesmas Ampenan sebanyak 68 orang. Teknik pengambilan sampel pada penelitian ini menggunakan sampel jenuh (total sampling). Variabel dalam penelitian ini yaitu usia ibu dan paritas sebagai variabel bebas, kejadian anemia dalam kehamilan sebagai variabel terikat. Instrumen penelitian ini berupa data dari buku KIA/KMS ibu atau register bidan di Puskesmas Ampenan. Teknik pengumpulan data menggunakan data primer dan sekunder. Analisis data meliputi analisis univariat dan bivariat dengan uji Chi Square dengan tingkat kemaknaan $\mathrm{p}<0,05$ dan tingkat kepercayaan $95 \%$.

\section{HASIL DAN PEMBAHASAN}

\section{Karakteristik ibu}

a. Umur

Karakteristik responden menurut umur di Wilayah Kerja Puskesmas Ampenan tahun 2017, ditunjukkan oleh tabel 1 berikut :

\section{Tabel 1}

Distribusi Responden berdasarkan umur di Wilayah Kerja Puskesmas Ampenan tahun 2017

\begin{tabular}{cccc}
\hline No & Umur & $\mathrm{f}$ & $\%$ \\
\hline 1 & Berisiko & 25 & 36,8 \\
2 & Tidak berisiko & 43 & 63,2 \\
\hline & Total & 68 & $100 \%$ \\
\hline
\end{tabular}

Pada tabel 4.4 menunjukkan distribusi responden berdasarkan umur di wilayah kerja Puskesmas Ampenan, bahwa lebih banyak ibu yang berumur antara 20-35 (tidak berisiko) yaitu sebanyak 43 orang $(63,2 \%)$.

\section{b. Paritas}

Karakteristik responden berdasarkan paritas di Wilayah Kerja Puskesmas Ampenan tahun 2017, ditunjukkan oleh tabel 2 berikut:

\section{Tabel 2}

Distribusi Karakteristik Responden Berdasarkan Paritas di Wilayah Kerja Puskesmas Ampenan Tahun 2017

\begin{tabular}{cccc}
\hline No & Paritas & f & $\%$ \\
\hline 1 & Primipara & 36 & 52,9 \\
2 & Multipara & 32 & 47,1 \\
\hline & Total & 68 & $100 \%$ \\
\hline
\end{tabular}

Pada tabel 4.6 terlihat bahwa sebagian besar responden berada pada kelompok paritas primipara yaitu sebesar 36 orang (52,9\%), sedangkan responden yang paling sedikit ada pada responden dengan paritas multipara yaitu sebanyak 32 orang $(47,1 \%)$.

\section{c. Pendidikan}

Karakteristik responden berdasarkan pendidikan di Wilayah Kerja Puskesmas Ampenan tahun 2017, ditunjukkan oleh tabel 3 berikut :

\section{Tabel 3}

Distribusi Responden Berdasarkan Tingkat Pendidikan di Wilayah Kerja Puskesmas Ampenan Tahun 2017

\begin{tabular}{cccc}
\hline No & Tingkat pendidikan & $\mathrm{f}$ & $\%$ \\
\hline 1 & Dasar & 19 & $27,9 \%$ \\
2 & Menengah & 39 & $57,4 \%$ \\
3 & Tinggi & 10 & $14,7 \%$ \\
\hline & Total & 68 & $100 \%$ \\
\hline
\end{tabular}

Pada tabel 4.5 terlihat bahwa kelompok pendidikan ibu paling banyak dalam kategori tingkat pendidikan menengah yaitu sebesar 39 orang $(57,4 \%)$, sedangkan responden paling sedikit berada dalam kategori tingkat pendidikan tinggi yaitu 10 orang $(14,7 \%)$.

\section{d. Usia Kehamilan}

Distribusi responden berdasarkan usia kehamilan di Wilayah Kerja Puskesmas Ampenan tahun 2017, ditunjukkan oleh tabel 4 berikut. 
Tabel 4

Distribusi Karakteristik Responden Berdasarkan

Usia Kehamilan di Wilayah Kerja Puskesmas Ampenan Tahun 2017

\begin{tabular}{cccc}
\hline No & Usia Kehamilan & f & $\%$ \\
\hline 1 & Trimester I & 25 & $36,8 \%$ \\
2 & Trimester II & 22 & $32,4 \%$ \\
3 & Trimester III & 21 & $30,9 \%$ \\
\hline & Total & 68 & $100 \%$ \\
\hline
\end{tabular}

Pada tabel 4 terlihat bahwa sebagian besar responden dengan usia kehamilan trimester I yaitu sebesar 25 orang $(36,8 \%)$, sedangkan sebagian kecil responden dengan usia kehamilan trimester III yaitu sebesar 21 orang $(30,9 \%)$.

\section{Kejadian anemia pada ibu hamil}

Distribusi responden yang mengalami anemia di Wilayah Kerja Puskesmas Ampenan Tahun 2017, ditunjukkan oleh tabel 5 berikut:

\section{Tabel 5}

Distribusi Frekuensi Anemia pada Ibu Hamil di Wilayah Kerja Puskesmas Ampenan Tahun 2017

\begin{tabular}{cccl}
\hline No & Anemia pada Ibu Hamil & f & $\%$ \\
\hline 1 & Ringan & 60 & 88,2 \\
2 & Berat & 8 & 11,8 \\
\hline & Total & 68 & $100 \%$ \\
\hline
\end{tabular}

Pada tabel di atas terlihat bahwa sebagian besar responden mengalami anemia ringan yaitu sebesar 60 orang $(88,2 \%)$, dan yang mengalami anemia berat sebanyak 8 orang $(11,8 \%)$.

3. Hubungan umur ibu dengan kejadian anemia dalam kehamilan di wilayah kerja Puskesmas Ampenan

Tabel 6

Analisis Chi Square hubungan antara umur ibu dengan kejadian anemia pada ibu hamil

\begin{tabular}{|c|c|c|c|c|c|c|}
\hline \multirow{3}{*}{ Umur Ibu } & \multicolumn{4}{|c|}{$\begin{array}{c}\text { Anemia dalam } \\
\text { Kehamilan }\end{array}$} & \multirow{3}{*}{$x^{2}$} & \multirow{3}{*}{$P$} \\
\hline & \multicolumn{2}{|c|}{ Berat } & \multicolumn{2}{|c|}{ Ringan } & & \\
\hline & $\mathrm{N}$ & $\%$ & $\mathrm{~N}$ & $\%$ & & \\
\hline Berisiko & 6 & 8,8 & 19 & 27,9 & & \\
\hline $\begin{array}{c}\text { Tidak } \\
\text { berisiko }\end{array}$ & 2 & 2,9 & 41 & $\begin{array}{c}60 \\
3 \\
\end{array}$ & $\begin{array}{c}5,70 \\
1\end{array}$ & $\begin{array}{l}0,01 \\
7\end{array}$ \\
\hline $\begin{array}{l}\chi^{2}=\text { Chi } \\
\text { Square }\end{array}$ & & & & & & \\
\hline
\end{tabular}

Tabel 6 menunjukkan hasil analisis chi square yang menyatakan bahwa terdapat hubungan yang bermakna antara umur ibu dengan anemia ( $p$ value $0,017<0,05)$.

4. Hubungan paritas ibu dengan anemia dalam kehamilan

Tabel 7

Analisis Chi Square hubungan antara paritas dengan kejadian anemia pada ibu hamil

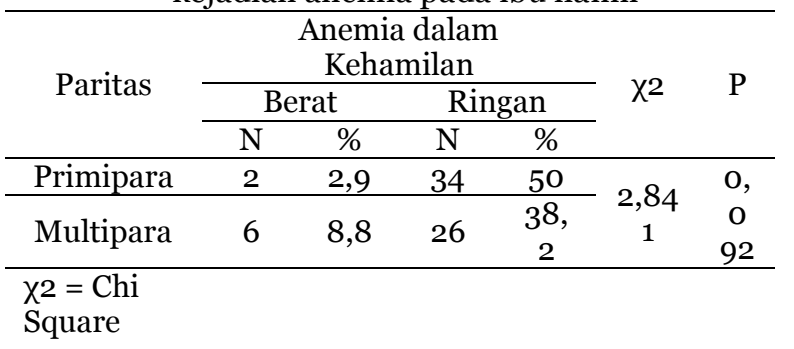

Tabel 7 menunjukkan hasil analisis chi square yang menyatakan bahwa tidak terdapat hubungan yang bermakna antara paritas dengan kejadian anemia pada ibu hamil ( $p$ value 0,092 >0,05).

\section{PEMBAHASAN}

\section{Usia ibu}

Hasil penelitian yang telah dilakukan di Wilayah Kerja Puskesmas Ampenan diketahui bahwa sebagian besar ibu hamil yang diteliti berada pada kelompok usia 20-35 tahun sebanyak 43 orang $(63,2 \%)$ dan sebagian kecil berada pada kelompok usia $>35$ tahun sebanyak 25 orang $(36,8 \%)$, dan hasil analisis chi square yang menyatakan bahwa terdapat hubungan yang bermakna secara statistik antara usia ibu dengan kejadian anemia di wilayah kerja Puskesmas Ampenan ( $p$ value 0,017 < 0,05). Hasil ini sesuai dengan penelitian Herawati tahun 2010, didapatkan bahwa usia ibu hamil yang mengalami anemia sebagain besar pada kelompok usia 20-35 tahun sebesar 87,7\%. Dari data dinyatakan bahwa mayoritas ibu hamil berada pada usia produktif untuk hamil dan melahirkan yaitu usia 20-35 tahun, usia tersebut organ-organ tersebut telah berfungsi dengan baik dan siap untuk hamil dan melahirkan namun bila dilihat dari segi psikologis pada kisaran usia tersebut masih tergolong labil [11] .

Hal ini sesuai dengan teori yang mengatakan bawah secara teori usia 20-35 tahun secara biologis mentalnya belum optimal dengan emosi yang cenderung labil, mental yang belum matang sehingga mudah mengalami keguncangan yang mengakibatkan kekurangan perhatian terhadap pemenuhan kebutuhan zat gizi terkait dengan pemunduran dan penurunan daya tahan tubuh serta berbagai penyakit yang sering menimpa diusia ini. Berbagai faktor yang saling berpengaruh dan tidak menutup kemungkinan usia yang matang sekalipun untuk hamil yaitu usia 20-35 tahun angka kejadian anemia jauh lebih tinggi [12].

Hal ini tidak sesuai dengan pendapat Wintrobe [13] menyatakan bahwa usia ibu dapat mempengaruhi timbulnya anemia, yaitu semakin rendah usia ibu hamil maka semakin rendah kadar hemoglobinnya. Muhilal (2009) dalam penelitiannya tentang hubungan antara faktor resiko dengan kejadian anemia menyatakan bahwa terdapat kecenderungan semakin tua usia ibu hamil maka presentasi anemia semakin besar. Pada penelitian ini belum menunjukkan adanya kecenderungan semakin tua usia ibu hamil maka kejadian anemia semakin besar. Sebanyak $80 \%$ ibu hamil berusia tidak berisiko yaitu antara 20 tahun hingga 35 tahun [14].

Demikian juga pendapat yang mengatakan bahwa usia merupakan salah satu faktor yang menyebabkan anemia terhadap kehamilan. Usia 20-35 tahun merupakan usia yang aman untuk menerima kehamilan dan persalinan. Karena pada usia tersebut organ reproduksinya sudah mulai berfungsi dengan baik. Pada usia <20 tahun ibu beresiko mengalami persalinan letal sungsang karena pada usia muda dengan kondisi panggul sempit sehingga memungkinkan ibu mengalami kesulitan dalam persalinan, sedangkan pada ibu yang berusia $>35$ tahun berhubungan dengan mulai terjadi regenerasi sel-sel tubuh terutama dalam hal ini adalah endometrium akibat usia biologis jaringan dan adanya penyakit yang dapat menimbulkan kelainan letak [15]. 


\section{Paritas}

Hasil penelitian yang telah dilakukan di puskesmas Ampenan dapat diketahui bahwa sebagian besar ibu hamil yang diteliti pada paritas primipara yaitu sebesar 32 orang $(47,1 \%)$. Dari data di atas peneliti mengasumsikan bahwa mayoritas ibu hamil berada pada paritas yang baru pertama kali hamil dan melahirkan yang biasanya masih mengalami kesulitan dalam beradaptasi dengan kehamilannya, dan pengetahuan serta pengalaman yang dimiliki seputar kehamilan juga masih lebih sedikit dibandingkan wanita dengan paritas tinggi.

Hal ini sesuai dengan pernyataan ahli yang megatakan bahwa paritas pertama mempunyai resiko lebih besar mengalami anemia pada kehamilan, apabila tidak memperhatikan kebutuhan nutrisi selama hamil. Berdasarkan hasil penelitian tersebut, maka dapat dijelaskan bahwa paritas merupakan salah satu faktor mempengaruhi anemia pada ibu. Pada umumnya semakin tinggi paritas ibu, maka semakin banyak pula pengalaman yang dimiliki oleh ibu tentang anemia. Namun hal ini menunjukan bahwa paritas atau pengalaman ibu menjadi tolak ukur untuk mengetahui tingkat pengetahuan yang dimiliki [16]. Teori yang meyatakan bahwa paritas atau jumlah anak yang dilahirkan oleh ibu baik yang hidup ataupun yang mati. Paritas dikatakan tinggi bila melahirkan anak ke empat atau lebih. Anak dengan urutan paritas yang lebih tinggi seperti anak kelima atau lebih kemungkinan menderita gangguan zat besi lebih besar. Tingkat paritas lebih menarik perhatian dalam penelitian terhadap hubungan kesehatan ibu yang berparitas rendah daripada yang berparitas tinggi [17].

Paritas 2 sampai 3 merupakan paritas paling aman ditinjau dari sudut kematian maternal maupun kesehatan ibu dan bayinya. Paritas 4 mempunyai resiko tinggi terkena anemia, hal ini disebabkan karena jumlah kelahiran (paritas) yang banyak dapat mempengaruhi keadaan kesehatan ibu sehingga ibu mudah terkena anemia [8]. Penelitian ini serupa dengan penelitian Amirudin (2010) menegaskan dalam penelitiannya tentang pasien anemia pada kehamilan di Rumah Sakit H.A Sultan Daeng Raja Kabupaten Bulukumba pada Tahun 2009 didapatkan hasil yaitu 52,2 \%, ini menunjukkan bahwa paritas tinggi atau jumlah anak 4 mempunyai resiko terkena anemia pada ibu hamil. Paritas tinggi mempunyai resiko 1,454 kali lebih besar untuk mengalami anemia dibandingkan dengan paritas rendah.

\section{Pendidikan}

Penelitian ini menunjukan bahwa ibu hamil yang anemia di puskesmas Ampenan kota Mataram mayoritas berpendidikan menengah sebesar 39 orang $(57,4 \%)$, sedangkan responden paling sedikit berada dalam kategori tingkat pendidikan tinggi yaitu 10 orang $(14,7 \%)$. Dari data di atas peneliti mengasumsikan bahwa pendidikan juga memiliki pengaruh yang penting dalam membentuk perilaku seseorang ke arah postif dan erat kaitannya dengan pengetahuan seseorang tentang sesuatu yang dibutuhkannya dalam hidup, terutama bagi ibu yang sedang hamil, pendidikan begitu penting dampaknya dalam meningkatkan pengetahuan tentang perilaku hidup bersih dan sehat yang benar sehingga anggota keluarganya terjaga dari penyakit. Semakin tinggi pendidikan, maka akan semakin tinggi daya serapnya terhadap informasi sehingga informasi-informasi yang didapatkannya dapat dipahami dengan baik. Sebaliknya, semakin rendah tingkat pendidikan, maka pola pikirnya menjadi rendah sehingga daya serapnya terhadap informasi juga menjadi kurang.

Hal ini sesuai dengan teori yang mengatakan bahwa pendidikan kesehatan berupaya agar masyarakat menyadari atau mengetahui bagaimana cara memelihara kesehatan mereka, bagaimana menghindari atau mencegah hal-hal yang merugikan kesehatan mereka dan kesehatan orang lain, kemana seharusnya mencari pengobatan bila sakit dan sebagainya [16]. Faktor pendidikan dapat mempengaruhi status anemia seseorang sehubungan dengan pemilihan makanan yang dikonsumsi. Tingkat pendidikan yang lebih tinggi akan mempengaruhi pengetahuan dan informasi tentang gizi yang lebih baik dibandingkan seseorang yang berpendidikan lebih rendah. Tingkat pendidikan berpengaruh terhadap perilaku hidup sehat. Pendidikan yang lebih tinggi memudahkan seseorang dalam menyerap informasi dan mengimplementasikan dalam perilaku dan gaya hidup sehari-hari, khusunya dalam hal kesehatan dan gizi. Tingkat pendidikan, khususnya tingkat pendidikan wanita mempengaruhi derajat kesehatan. Tingkat pendidikan seseorang mempengaruhi pengetahuan dan pemahamannya terhadap sesuatu dan mengarahkannya ke perilaku positif, demikian juga tentang perilaku kesehatan, sehingga dapat dikatakan bahwa semakin tinggi pendidikan seseorang, maka semakin baik pula tingkat pengetahuannya mengenai anemia. Sebaliknya semakin rendah tingkat pendidikan, maka pola pikirnya menjadi rendah sehingga daya serapnya terhadap informasi juga menjadi berkurang [18]

\section{Usia Kehamilan}

Hasil penelitian yang telah dilakukan di Puskesmas Ampenan dapat diketahui bahwa bahwa sebagian besar responden dengan usia kehamilan trimester I yaitu sebesar 25 orang (36,8\%), sedangkan sebagian kecil responden dengan usia kehamilan trimester III yaitu sebesar 21 orang (30,9\%). Dari data tersebut peneliti mengasumsikan bahwa mayoritas responden dengan usia kehamilan trimester I, tentunya hal ini berpengaruh terhadap kesehatan ibu itu sendiri yang sedang mengalami kehamilan karena biasanya wanita dengan usia kehamilan muda lebih rentan terkena anemia sehingga kadar hemoglobinya yang mengalami penurunan, meski tidak ada teori yang menjelaskan kaitan usia kehamilan dengan kejadian anemia pada ibu hamil.

Anemia kehamilan atau kekurangan kadar hemoglobin (Hb) dalam darah dapat menyebabkan komplikasi yang lebih serius bagi ibu dalam kehamilan, persalinan dan nifas yaitu dapat megakibatkan abortus (keguguran), partus prematur, kelahiran bayi prematur, berat bayi lahir rendah, perdarahan post partum karena atonia uteri, syok, infeksi intra partum maupun post partum [19]. Usia kehamilan ibu berpengaruh terhadap kejadian anemia, dimana usia kehamilan yang masih muda membutuhkan asupan gizi yang lebih sehingga ibu dengan usia muda rentan menderita anemia dalam kehamilan dan akan sangat rentan terhadap infeksi dan perdarahan, walaupun perdarahan hanya sedikit. Pengalaman membuktikan bahwa kematian ibu karena perdarahan lebih sering terjadi pada para ibu yang menderita anemia [15].

Kebutuhan zat besi pada saat kehamilan meningkat. Beberapa literatur mengatakan kebutuhan zat besi meningkat dua kali lipat dari kebutuhan sebelum hamil. Hal ini terjadi karena selama hamil, volume darah meningkat 50\%, sehingga perlu lebih banyak zat besi 
untuk membentuk hemoglobin. Selain itu, pertumbuhan janin dan plasenta yang sangat pesat juga memerlukan banyak zat besi. Dalam keadaan tidak hamil, kebutuhan zat besi biasanya dapat dipenuhi dari menu makanan sehat dan seimbang. Tetapi dalam keadaan hamil, suplai zat besi dari makanan masih belum mencukupi sehingga dibutuhkan suplemen berupa tablet besi. Pada kehamilan rentan terjadi anemia karena ibu hamil mengalami hemodilusi (pengenceran) dengan peningkatan volume $30 \%$ sampai $40 \%$ dan puncaknya terjadi pada kehamilan 32 sampai 34 minggu. Jumlah peningkatan sel darah sebesar $18 \%$ sampai $30 \%$ dan hemoglobin sekitar 19\%. Terjadinya hemodilusi akan mengakibatkan secara fisiologis terjadi anemia pada kehamilan. Untuk menanggulangi masalah anemia pada ibu hamil pemerintah melalui Departemen Kesehatan RI melaksanakan suatu program pemberian tablet zat besi pada ibu hamil, karena ini merupakan upaya penting dalam pencegahan dan penanggulangan anemia. Akan tetapi dalam kenyataannya, tidak semua ibu hamil yang mendapat tablet zat besi meminumnya secara rutin, hal ini bisa disebabkan karena faktor ketidaktahuan pentingnya tablet zat besi untuk kehamilannya.

\section{Anemia pada ibu hamil}

Dalam penelitian ini ditemukan sebagian besar responden yang menderita anemia ringan ( $\mathrm{Hb} 8-<11$ gr\%) yaitu sebesar 60 orang $(88,2 \%)$ dibandingkan dengan responden yang mengalami anemia berat $(\mathrm{Hb}<8$ gr\%) sebesar 8 orang $(11,8 \%)$. Dari data tersebut peneliti mengasumsikan bahwa mayoritas responden mengalami anemia ringan yang berarti bahwa ibu hamil memiliki kadar hemoglobin kurang dari 11 gr\% namun ini berbahaya bila dilihat dari resiko kehamilan. Sesuai dengan teori yang mengatakan bahwa nilai ambang batas yang digunakan untuk menentukan anemia pada ibu hamil yaitu dimana kadar hemoglobin ibu kurang dari 11 gr\% [20]. Konsentrasi hemoglobin normal (11 gr\%) pada wanita hamil berbeda dengan wanita yang tidak hamil. Hal ini disebabkan karena pada kehamilan terjadi proses hemodilusi atau pengenceran darah, yaitu terjadi peningkatan volume plasma dalam proporsi yang lebih besar jika dibandingkan dengan peningkatan eritrosit. Ekspansi volume plasma di mulai pada minggu ke-6 kehamilan dan mencapai maksimum pada minggu ke-24 kehamilan, tetapi dapat terus meningkat sampai minggu ke-37. Hemodilusi berfungsi agar suplai darah untuk pembesaran uterus terpenuhi, melindungi ibu dan janin dari efek negatif penurunan venous return saat posisi terlentang (supine), dan melindungi ibu dari efek negative kehilangan darah saat proses melahirkan [21].

Kebanyakan anemia dalam kehamilan disebabkan oleh defisiensi besi dan perdarahan akut bahkan tidak jarang keduanya saling berinteraksi. Kebutuhan ibu selama kehamilan ialah $800 \mathrm{mg}$ besi, diantaranya $300 \mathrm{mg}$ untuk janin dan 500 mg untuk pertambahan eritrosit ibu. Dengan demikian ibu membutuhkan tambahan sekitar 2-3 mg besi/hari (Saifuddin, 2010). Wanita hamil memerlukan zat besi dalam jumlah banyak yang tidak didapat dari makanan saja untuk itu perlu mendapat suplemen besi mencapai $100 \mathrm{mg}$ selama kehamilan. Apabila wanita hamil menderita anemia defisiensi besi dengan kadar haemoglobin kurang 10 gr\% dapat ditambah 600-1000 $\mathrm{mg} /$ hari zat besi seperti Sulfas Ferosus atau Glukosal Ferosus. Terapi oral diberikan terus menerus selama 3 bulan. Dari data di atas menunjukkan bahwa di Puskesmas
Ampenan masih terdapat ibu yang menderita anemia. Hal ini terjadi karena adanya faktor lain yaitu kurangnya pemahaman tentang pola makan dan menu seimbang. Sehingga asupan gizi ibu kurang terutama zat besi dan asam folat pada bahan makanan yang di konsumsi sehinggga ibu mengalami anemia [20].

Hal ini perlu dilakukan penanganan anemia adalah dengan preparat besi yang diminum (oral) atau dapat juga dengan cara suntikan (parenteral). Contoh pemberian preparat besi dengan cara terapi oral yaitu fero sulfat, fero gluconat dan Na-fero bisitrat dengan pemberian 60 $\mathrm{mg} /$ hari untuk menaikkan kadar hemoglobin. Contoh pemberian preparat parenteral yaitu dengan ferum dextran sebanyak $1000 \mathrm{mg}(20 \mathrm{ml})$ secara intravena dengan tujuan untuk meningkatkan kadar hemoglobin dengan cepat, pemberian secara parenteral ini harus berdasarkan indikasi misalnya pada penderita dengan anemia berat [22].

\section{SIMPULAN DAN SARAN}

\section{Simpulan}

Dari hasil penelitian yang dilakukan di wilayah kerja Puskesmas Ampenan tentang usia ibu dan paritas , maka dapat disimpulkan :

1. Sebagian besar responden mengalami anemia ringan yaitu sebesar 60 orang $(88,2 \%)$, dan yang mengalami anemia berat sebanyak 8 orang $(11,8 \%)$.

2. Distribusi responden berdasarkan umur di wilayah kerja Puskesmas Ampenan, bahwa lebih banyak ibu yang berumur antara 20-35 (tidak berisiko) yaitu sebanyak 43 orang $(63,2 \%)$, dan sebagian besar responden berada pada kelompok paritas primipara yaitu sebesar 36 orang $(52,9 \%)$, sedangkan responden yang paling sedikit ada pada responden dengan paritas multipara yaitu sebanyak 32 orang $(47,1 \%)$.

3. Ada hubungan yang bermakna antara umur ibu dengan anemia ( $p$ value $0,017<0,05$ ), dan tidak tidak terdapat hubungan yang bermakna antara paritas dengan kejadian anemia pada ibu hamil ( $p$ value $0,092>0,05$ ).

\section{Saran}

1. Bagi Ilmu Pengetahuan

Diharapakan untuk menambah literatur ilmu pengetahuan dalam pengembangan ilmu serta sebagai tambahan literatur atau informasi dalam melakukan penelitian selanjutnya.

2. Bagi Pengguna

a. Bidan Puskesmas

Diharapkan dengan penelitian ini kepada bidan di Puskesmas Ampenan agar lebih memperhatikan ibu-ibu hamil yang mengalami anemia dengan melakukan penyuluhan kesehatan dan perawan ibu hamil serta memberikan bimbingan tata cara pemeliharaan kesehatan selama kehamilan.

b. Bagi Masyarakat

Masyarakat khususnya ibu-ibu hamil diharapkan bila ingin hamil, sebaiknya di usia yang ideal, tunda kehamilan dengan menggunakan alat kontrasepsi, dan lakukan 
pemeriksaan kehamilan secara rutin dan rajin mengkonsumsi tablet $\mathrm{Fe}$ selama kehamilan.

\section{UCAPAN TERIMA KASIH}

Tim penulis mengucapkan terima kasih kepada LPPM Universitas Muhammadiyah Mataram yang telah mendanai penelitian ini, dan berbagai pihak yang telah banyak membantu dalam proses penelitian.

\section{DAFTAR RUJUKAN}

Daftar rujukan ditulis dengan font 9 pt, spasi 1.

[1] Riskesdas, Badan Penelitian dan Pengembangan Kesehatan Kementrian Kesehatan RI. 2013.

[2] Depkes RI, Profil Kesehatan Indonesia, 2010.

[3] Dinkes Provinsi NTB, Profil Kesehatan Provinsi NTB, 2015.

[4] WHO, Maternal Mortality, 2015.

[5] Kemenkes RI, Buku Kesehatan Ibu dan Anak. Direktorat Kesehatan Keluarga, Jakarta, 2013.

[6] Dinkes Kota Mataram, Profil Kesehatan Kota Mataram, 2016.

[7] Winkjosastro, Ilmu kebidanan, Yayasan Bina Pustaka, Jakarta, 2007.

[8] Arisman. Buku Ajar Ilmu Gizi Keracunan Makanan. EGC, Jakarta Hal. 93, 2004.

[9] Manuaba. Pengantar Kuliah Obstetri. Buku Kedokteran EGC, Jakarta, 2010.

[10] Herawati, C. \& Astuti, S. Faktor-faktor yang Berhubungan dengan Anemia Gizi pada Ibu Hamil di Puskesmas Jalaksana Kuningan Tahun 2010. Jurnal Kesehatan Kartika, 2010.

[11] Varney H. Buku Ajar Asuhan Kebidanan (Varney's Midwifery), edisi 4, cetakan 1, EGC, Jakarta, 2009.

[12] Niven. Psikologi Kesehatan Pengantar Untuk Perawat dan Profesional Kesehatan Lain, EGC, Jakarta, 2012.

[13] Muhilal, dkk. Prinsip Dasar Ilmu Gizi. PT. Gramedia Pustaka Utama, 2007.

[14] Prawiroharjo S. Ilmu Kebidanan, Yayasan Bina Pustaka, Jakarta, 2009.

[15] Notoadmodjo. Metodologi penelitian kesehatan, Jakarta, Rineka Cipta, 2010.

[16] Sarwono. Buku Pedoman Praktis Pelayanan Maternal dan Neonatal, Yayasan Bina Pustaka, Jakarta, 2008.

[17] Ekowati. Peran suami dalam pemeliharaan status gizi ibu hamil di Wilayah kerja Puskesmas Baturaden Kabupaten Banyumas: Universitas Jenderal Soedirman Purwokerto, Purwokerto, 2007.

[18] Hidayah. W. dan Anasari, T. Hubungan Kepatuhan Ibu Hamil Mengkonsumsi Tablet Fe Dengan Kejadian Anemia Pada Ibu Hamil di desa Pagiragi kecamatan Cilongok Kabupaten Banyumas, 2012.

[19] Proverawati. Anemia dan Anemia kehamilan, Nuha Medika, Yogyakarta, 2011.

[20] Cunningham. Obstetri William, EGC, Jakarta, 2007.

[21] Wasnidar. Buku Saku Anemia Pada Ibu Hamil, Konsep dan Penatalaksanaan, Jakarta, 2007. 